\title{
Living in a Minority Food Culture: A Phenomenological Investigation of Being Vegetarian/Vegan
}

Sachi Edwards, University of Maryland, College Park, MD

Email: sachiteresa@gmail.com

\begin{abstract}
This phenomenological investigation aims to explore the lived experience of being vegan or vegetarian in a society and culture that is primarily non-vegetarian. As members of a unique minority group, vegans and vegetarians can sometimes be misunderstood by non-vegetarians and stereotyped as judgmental or difficult to deal with. Living with this type of misunderstanding from others can lead to feelings such as worry, loneliness, and fear. As such, the use of phenomenological inquiry is well suited to uncover the lived experience this phenomenon in such a way that no other method of inquiry could. The author brings forward themes that emerged from in depth conversations with two vegan/vegetarian participants, and draws from her own personal experiences as a vegetarian to supplement the data and further uncover the phenomenon. Themes are brought forward through the use of, among other works, Hyppolite's (1956) and Bachelard's (1994) descriptions of “inside vs. outside” and van Manen and Levering's (1996) notion of secrecy.
\end{abstract}

\section{Introduction}

I had been planning it all day. As soon as I get off work, I'm gonna do it...

It was something I had never done before. My heart was racing as I watched the clock. It was dark and chilly as I drove across the parking lot, constantly looking behind me to make sure no one was watching. I handed over the money, and got what I asked for in return. She treated it as if it was no big deal. Somehow I thought that it would be more serious than that; she would judge me, or that she would be able to sense my nerves and know it was my first time. I didn't look at it right away; I just drove off. I went to a friend's house. He was having a party that night. I called two of my best friends and asked them to meet me outside. Don't tell anyone it's me calling and don't tell them where you are going! I wanted to share my first time with them, but I couldn't bear the thought of anyone else knowing. We sat on the curb behind my car, giggling like little girls who knew they were doing something wrong. My friends had both done this countless times and they always told me how good it was. Only recently had I begun to get curious about it and tonight, for the first time, I let myself give in to temptation.

I opened the bag and took it out. It smelled good; it was a familiar smell but not one I could say I ever linked to the taste. I'm so nervous, guys! What if someone finds out? You have to swear not to tell anyone. I peeled back the wrapper, opened my mouth, and took a bite ... a Burger King crispy chicken sandwich.

This seems like such a simple moment - sharing a fast food meal with my girlfriends but it was one that I had never experienced before. Prior to this moment, I had been a full- 
fledged vegetarian for my entire life, over 17 years: no meat, no fish, not even Jell-O, or gummy bears. School lunches, birthday parties, post-soccer game potlucks, sleeping over at friends' houses; all "normal” events in a child's life that are typically fun and happy memories. Yet, for me, they were nerve-racking and, at times, shameful. I was "that girl” ... the girl who didn't eat meat, whose parents made special arrangements with the lunch lady at elementary school so I could have peanut butter sandwiches instead of Sloppy Joes, who brought her own tofu hot dogs to the barbeque, who couldn't participate in the beef jerky fundraiser for my dance group. I was so often made brutally aware of the extreme social implications that food carried; something that most people around me didn't seem to understand. Certainly, no one else understood why eating my first chicken sandwich was such a big deal. But, as a vegetarian, it carried so much more weight than someone for whom a chicken sandwich is a normal - even mundane - meal. As a vegetarian, meat was not normal, but for everyone else meat was normal, and it was me who was abnormal.

As a child of vegetarian parents, I was raised in a strictly vegetarian household. However, none of my extended family members from either side were vegetarian, and none of my close friends were vegetarian either. My diet became a very integral part of my identity, both for me and everyone who knew me. When I started to experiment with non-vegetarian food after high school, I still identified as a vegetarian. Despite occasionally sneaking a piece of shrimp from a friend's plate, I did not want to let go of my vegetarian identity, and tried my best to maintain that image of myself in the eyes of others. Everyone I was acquainted with knew me as a vegetarian and I was scared to let that identity slip away.

In college, I began to live more freely as a meat eater. For a few years, I experienced mainstream life by participating in the dominant food culture. After a while, however, I began meeting other people my age who were vegetarian or vegan - prior to this I had never met other vegetarians aside from my parents' friends. I felt a connection with them, as companions in the minority food culture, but had to face the truth that I was no longer a part of that way of being in the world-meatless. Feeling that connection, the sense that they understood my childhood experiences, made me long to be vegetarian again.

Shortly after college, I decided that I did not want to eat meat anymore. The decision to go back to vegetarianism made me happy, like reconnecting with my culture - my minority food culture. Strangely, though, explaining this decision to those who now knew me as a meat eater was quite difficult. Most people tried to be considerate, but I sensed that they were secretly annoyed. It was like having to explain myself for being who I truly wanted to be - who I had been for most of my life - not the meat eater they thought I was. The transition back into vegetarianism was just as hard as the transition out of it. Needless to say, food has been the source of a great deal of tension in my life. This is an experience that those who have lived in the dominant food culture their whole lives may struggle to understand.

My unique experience with vegetarianism has always made me curious about how other vegetarians or vegans experience living in a world that is primarily non-vegetarian. Do others experience as much difficulty with food as I have had? What is the experience of those who are the only vegetarian or vegan in a family full of meat-eaters? What is the experience of explaining their decisions to loved ones who simply want to share a special meal with them? What is the experience of "coming out" to their non-vegetarian family and friends while attempting not to sound judgmental about their food choices? The phenomenon of choosing and living a vegetarian or vegan lifestyle in a predominantly meat-eating environment is highly complex, 
multi-layered, and surely deserving of deep phenomenological inquiry. Thus, my journey to uncover the lived experience of being a vegetarian/vegan begins.

\section{Existential Investigation}

Food is one of the most essential elements of life, right next to air, water, and shelter. Everyone eats because everyone needs to eat. As such, food becomes a converging point to which everyone can relate, and eating becomes a favorite pastime in many social, familial, romantic, and even professional situations. Relationships are built around food. Sharing food fills awkward spaces, facilitates budding friendships and solidifies partnerships. However, what is the experience of those who decide not to partake in a given meal the same way as everyone else does? How might one experience the development of a new relationship without the ability to share food?

When choosing to live a vegetarian or vegan lifestyle, it can sometimes feel like one then has a different relationship with the space around them than those who have a more conventional diet. What others see as food - in a grocery store, a food court, on a billboard or television - a vegetarian may see as something other than that; something taboo, unappealing, or simply not an option and may as well not be there. Vegetarians may experience a multitude of everyday events very differently than non-vegetarians. After all, it is customary in most cultures to eat meat when celebrating holidays, acknowledging special occasions, or simply having dinner. However, when choosing not to eat meat for dinner, special occasions, or holidays, the way you see and deal with food may be an entirely different experience.

After returning from a long period of time immersed in an indigenous community, David Abram (1996) observed his own discomfort being with his surroundings differently than those around him. While away, he sensitized himself to the intricate details of life in the present moment, and then felt strange to be, once again, immersed in Western culture and living amongst those who are too busy and stressed out to see what he calls the "Sensuous presence of the world" (Abram, 1996, p. 201). So, too, in the context of a meat-eating culture, vegetarians have a strange way of being with food, and thus with the world. They may feel excluded from the mainstream Western worldview and from the secret relationship with food that everyone else seems to have, one that they may have known at one time, but they are no longer privy to. While the rest of the group is exchanging their thoughts about how great the non-vegetarian main course is, the vegetarian might be left with nothing to contribute until the conversation moves on to the vegetarian/vegan appropriate side-dishes, leaving the vegetarian on the outside of the discussion about the focal point of the meal, which is only for the meat-eaters - i.e. the insiders.

Gaston Bachelard (1994) elaborates on the notion of inside vs. outside, claiming that the natural division of the two can cause, at times, feelings of anger or isolation. Philosopher Jean Hyppolite says, "You feel the full significance of this myth of inside and outside in alienation, which is founded on these two terms. Beyond what is expressed in their formal opposition lie alienation and hostility between the two" (Bachelard, 1994, p. 212). Indeed, vegetarians are outsiders in the world of eating meat, and are then faced with the challenge of dealing with the possibility of anger, or hurt feelings - either on their end, or from others. Might the feeling of exclusion from a meal leave the vegetarian bitter that everyone else was able to satisfy himself or herself and they were not? Conversely, might the feeling of rejection on the part of one who is attempting to feed a vegetarian leave that person feeling inadequate or unappreciated? Surely 
there is room for tension to arise, even if founded on untruths. The reality of being left out can cause fear of possible judgment or resentment. Van Manen and Levering (1996) state that, "When people feel excluded, [it] is quite often the result more of misunderstanding than of deliberate ostracism ... some people exhibit mild paranoia in their suspicions of being excluded" (p 79). If a vegetarian/vegan perceives that a non-vegetarian carries resentment towards him/her, it can lead to feeling of alienation, whether or not the perceived resentment is real. Sadly, this perceived exclusion could prohibit a vegetarian/vegan from being open to the possibility that others might not actually feel inconvenienced by their food choices.

For those who do not have self-imposed dietary restrictions, understanding what it feels like to live with them can be difficult. Vegetarians and vegans constitute a unique kind of minority group; one based on choice, not by biological trait. They are often surrounded by the dominant non-vegetarian group, leaving them to navigate their way through each meal alone sometimes this extends into their own families and homes. This experience of being left to traverse the rugged path towards each meal by yourself can produce a sense of loneliness. Sure, there are people around you, so you are not physically alone, but you are alone in your thoughts and feelings, which can make it difficult to feel connected to your surroundings. Anna Kirova (2005) explains that, "Loneliness prevents us from bringing things near us. Loneliness estranges and separates us from the things around us and thus destroys the mutual appropriation of our being toward one another” (p. 158). Being lonely in an experience can be just as lonely as actually being alone - possibly even more so. When we are alone and we feel lonely, our mind tells us that our feelings of loneliness are normal. When we are with others and we feel lonely, we become self-conscious, unsure of what to do and how to behave, hesitant to make eye contact or to slouch our shoulders and let our gut hang out, worried that those around us are watching us and can sense our loneliness. Yet, for vegetarians, eating with others (often, non-vegetarians) is a requirement in many ways for our social standing and our reputation in various circles - thus, vegetarians may find themselves with no choice but to struggle through these uncomfortable situations on their own.

Being a host, or being hosted, presents even more pressure than simply eating in the presence of others. Elizabeth Telfer (1996) raises the issue of hospitality in relation to food, emphasizing the connection between hospitality and friendship: "Giving, receiving, and sharing food is a symbol of the bond of trust and interdependency set up between host and guest” (p. 83), she explains, making a simple meal so much more than just a meal. As a vegetarian guest, should you take meat if is presented to you? Would you experience more discomfort if you accepted it and then left it on your plate, or if you outright denied the offer? As a vegetarian hosting nonvegetarians, you are anxious and ask, will the guests be pleased with a meatless meal? Will you be worried all evening about the potential that they are whispering to one another about the lackluster spread you have provided? In light of these unanswered questions, the pressure surrounding hosted meals may weigh heavily on the shoulder of vegetarians who could become extremely sensitive to the ways in which their life choice inevitably affects others. What may seem like a personal choice that you decide to impose on yourself, might reverberate into areas of your life that you never thought possible.

Given the societal importance of food in most cultures, and the ability food has to draw attention to those who do not experience it the same way, it is possible that vegetarians and vegans feel marginalized in some ways throughout their day-to-day lives by the meat-eating majority. A phenomenological investigation is well-suited to show those experiences as shared by the participants in this study. The purpose of this research is to discover the ways in which 
vegetarianism affects the lives of those who live it, and to grasp a deeper understanding of what it means to be in this world as a vegetarian.

\section{Research Participants}

In order to understand the lived experience of vegetarianism deeper than I am able to understand it on my own, I recruited the help of two women who graciously guided me through their inner thoughts and feelings surrounding their life as vegetarians. ${ }^{\mathrm{i}}$ Malia, a college senior, has been a vegetarian for almost four years, and a vegan for much of that time as well. She cites many reasons for her vegetarianism/veganism: "I can't think of a good reason not to be a vegetarian... there isn't one (Malia)," although after many conversations with her, most of her explanations suggest that her primary reason is her concern over the treatment of animals in the meat and dairy industries. She was raised in a "meat and potatoes everyday" household. But, shortly after she announced her vegetarianism, her two sisters also became vegetarian. Now, even though all three of her parents' children are vegetarian, her parents are still predominantly meat eaters.

Jessica, a mother of three, is a graduate student and a home school teacher, and has experimented with various degrees of vegetarianism, on and off, since childhood, but has been maintaining vegetarianism for the last four years. She explains that eating meat has become too uncomfortable for her because the pain of thinking about eating what was once a live animal is too great. She was raised eating meat, and has married into a family with a strong and enduring tradition of hunting and fishing. As such, she is the only one on both her and her husband's side of the family that is a vegetarian, including her three children.

Malia, Jessica, and I all have very different experiences with vegetarianism, and also have different reasons for being vegetarian. My concern here is not why or how one is a vegetarian. The primary goal of this research is to elucidate the experience of being a vegetarian while surrounded by - and/or in relation to - those who are not vegetarian. The following themes have come forward in my conversations with both Malia and Jessica, and have echoed true in my own life experiences.

\section{Hope We Can Still Be Friends: Worrying About the Social Implications of Your Diet}

Worry may be part of many everyday experiences; it may hinder our ability to relax, and to enjoy what should be a pleasurable experience. Or, worry may escalate to anxiety, leaving us wretched, debilitated, even incapacitated. While vegetarians may worry about the food on their plates, perhaps it is more than food that worries the vegetarian - such as our relationships with others.

When Jessica attempted to establish a new friendship circle in a new town, her vegetarianism almost got in the way. She joined a book club with some of the other mothers in the area and looked forward to having some time away from "mommy duties." On her way to the house of the woman who was hosting book club, she called to ask for directions, as she was still fairly new to the neighborhood. In her excitement, she shared that she was hungry and looking forward to the food - a statement that upon later reflection she wished she had not made. Upon arrival, she realized that dinner would be plated and served, instead of the buffet style presentation she was expecting. Her usual tactics of selective self-serving would not allow her to fly under the radar this time. She stared at the plate in front of her, trying to think of what to do. 
Her heart was racing, and the voice in her head was telling her: Eat! Just a little bit. Be gracious to the host. Just taste what she has given you. As Telfer (1996) explained, food is a symbolic bond between host and guest, and Jessica certainly did not want to miss out on creating a new friendship. But, how could she bring herself to do it? The thought that those little brown chunks strewn throughout the dish used to be alive, used to have a face, made her tense up even more than the thought of admitting she was a vegetarian. If only she had not said that she was hungry on the phone, then she could have lied and said that she had a late lunch. That way, she might have been able to leave her impression on the host as "the friendly one" or "the new one" or "the one with the cute dress" rather than "the one that didn't eat what I served.”

I remember thinking about how I was new in town and here I am, putting up the flag and everybody else is sitting enjoying their plate and I had to just sit there at this big table without anything on my plate for that course (Jessica).

She feels lonely. She is in a room full of potential new friends, but she feels alone in her thoughts, and she worries that his loneliness is separating her from the group, something Kirova (2005) warned loneliness could do. To make amends for denying the food her host had put time, care, and money into making, she made a point of raving about how amazing the salad was, complete with smiles and yummy noises, all the while thinking, "I hope she still likes me, I hope I didn't hurt her feelings, I hope we can still be friends (Jessica).”

The word worry can be traced back to the Old English word, wyrgan, meaning, "to strangle” (Online Etymology Dictionary [OED]). When we worry, it feels like we are literally strangled by our thoughts as the gravity of the situation closes in and tightens around our very selves. Breaths shorten and words stumble out of our mouths nonsensically. And although we may try to salvage the situation in the best way we know how, after the moment is over, we still may be plagued by worry: "I hope we can still be friends."

As a member of this minority food culture, I am aware of the burden I might place on others simply by being present in an environment of food. The fear that others may worry about me, or that they may feel downright resentful that I choose not to eat their food, overcomes me whenever I see meat products presented or served. Am I incapable of being hosted? Will my host understand that it is not my intention to reject their hospitality? I am reminded of a vivid memory from my recent past.

My fiancé and I were out doing errands and we stopped at his father's house to pick up a few things. There were steaks on the grill and dinner was about to be served. My future father-inlaw asks us, "Have you guys eaten?” “No,” my fiancé replies as he looks to me for approval to stay and eat. On the outside I smile, "sure we can stay." On the inside, I cringe, my stomach tightens up into a ball and I instantly realize how hungry I really am; I knew would not be eating any time soon, at least not anything substantial. Why couldn't I just tell my fiancé it was a bad idea to stay? Simply, because I did not want to upset my soon-to-be-husband's father by rejecting his dinner invite, and because my poor fiancé is drooling at the chance to eat a steak when all I feed him in our home is veggies and legumes. We sit down and there are three food items on the table: steak, white bread rolls, and raw baby carrots. I take a bread roll and a handful of carrots - hardly anyone else has touched the carrots. Perhaps they think that they are just for show? Then I hear someone say, "I think there might be a veggie burger in the freezer. Do you want me to heat it up for you?” I decline. I certainly would not want anyone to get up from their meal to make me something special. "These carrots and bread rolls are great!” I say. When we are done, my fiancé quietly suggests to me that we call in an order to the nearby Chinese restaurant. "We can pick it up on the way home," he says. My whole body stiffens. I blush with 
embarrassment. "Shhhhhhhh!” I say as quietly as I can, trying not to move my lips or draw any attention to myself, "We'll figure it out after we leave." In this moment, would rather starve than have his family hear me make a food order right after they "fed" me dinner.

The inevitable sense of worry may make shared meals especially hard. Food may be a representation of someone's love, care, or appreciation such that vegetarians may fear making others feel as if they were not grateful for others' efforts to feed them, to share with them.

To share means, "to divide one's own and give part to others." It also means, "to use, participate in, enjoy, or receive” (OED). We may wonder if we are not able to fully share in a meal, what else may we be left lacking? What else may we not be giving? The fact that someone else has divided his/her own food and offered part to us means, that if we do not accept it, we are rejecting their attempt to share. How can a relationship be built if one rejects the other? How can we participate in, or enjoy, a relationship if we don't receive what others are giving? Certainly, it may become more difficult; hence the anxiety vegetarians may have surrounding food-inclusive events.

Even when removing the situation from someone's home, in essence removing the "host" and the potential of having to reject their offering, the worry about being unable to share food persists. After all, even when no one is "hosting" a meal, meals in the company of others are still meant to be a shared experience. For example, when going to out to eat at a restaurant, the goal is still to share a meal with others - to participate in and enjoy the meal together. But, when others notice that what you are eating is different than what they are eating, or if they feel somehow that what you are eating is inadequate, then the meal may not actually feel like a shared one, and again the vegetarian may be left feeling the guilt of causing the discomfort. Therefore, worrying about others and the need to "protect" others from worrying still may be a significant part of the vegetarian's experience.

Malia recalls a weekend trip that she took with her boyfriend and several of his friends. "I asked my boyfriend not to tell any of his friends that I was a vegan. I would rather fend for myself than have them worry about me all weekend" (Malia). She ended up at a restaurant that only had one vegan option and even though it did not sound very appealing, she ordered it because she was afraid that asking the waiter to remove the cheese from one of the other menu items would not only be a burden on the waiter, it would give away the fact that she was vegan and would probably make her boyfriend's friends feel bad about the restaurant they chose - and she did not want that. Had she been there with other vegans, she might have worked up the nerve to customize her order as she would have liked it because then at least those she was with would understand her. But, she was not, and she felt that being able to order something quick and straight off the menu diminished any attention put on her. She fumbled her way through an underwhelming meal, but did not dare say anything about her disappointment. To her, keeping up the ruse of a shared meal was more important than eating something delicious.

For Jessica, keeping her family members satisfied during a shared meal means eating more than she otherwise would. From her perspective, this eases their concern about her eating what they perceive to be an insufficient amount of food, and makes them feel more as if the meal is truly shared. Ironically, one of Jessica's favorite restaurants is a steak house - after all they have great salad, bread, baked potatoes, and of course, chocolate cake! But for some reason, because she is not eating steak, which is what her family is eating, they tend to express concern that she is not eating enough. So instead of just ordering her favorite salad and a baked potato, which is all she really wants, she will also order an appetizer, and even though she usually ends 
up sharing it with everyone at the table, the fact that she has ordered something (anything!) to replace the empty hole left by the lack of steak, they seem happy.

Because we need to eat multiple times a day, the chances of vegetarians encountering a situation in which they might feel the need to compensate for their lifestyle choice are high. The learning curve is steep for new vegetarians, as food is not something people in the West typically have to worry about, but the fact that those who have chosen to be vegetarian or vegan are willing to deal with the added anxiety and stress of living in a majority meat-eating society may indicate the strength of their feelings surrounding food and eating. If it is easier and more convenient to eat meat, yet someone still choses not to, they clearly have a strong commitment to their reasoning. Malia admits being happy with her decision to become a vegetarian despite how difficult it can be and how it affects others. "I didn't really think about the consequences, it was kind of something I learned along the way, but not eating meat is important to me and that is kind of a reflection of who I am” (Malia).

\section{Why Don't They Understand Me?: Experiencing the "Normal" Abnormally}

When I first started to think about spending the rest of my life with my fiancé, the only thing that made me worry was the fact that he was not a vegetarian. Will he end up resenting me for not cooking meat? Will he make it a habit of picking up fast food on his way home from work and then decline the meal I so lovingly prepared for him? How would we raise our future children? I remember trying to talk to my girlfriends about it. However, all any of them said was, "Oh my gosh, food is such a non-issue, why are you so concerned about it?” Maybe I should have taken that as a compliment, that I had done such a good job of hiding my food anxiety around them that they could not understand why I was now worried about it all of a sudden. But what do they know?! I bet they never had to go hungry at a potluck party! They probably never had to stop and get something to eat on the way home from a Thanksgiving dinner! I suppose people might not realize how significant something is until it is taken away from them; and many nonvegetarians may not to realize how significant the issue of food really is to vegetarians.

The word "food" can be traced back to both the Old English word "foda," meaning nourishment or fuel, and to the Germanic root word "fod," which means to protect, to guard, or to feed (OED). Our understanding of food as a basic, indispensable part of our lives that protects and guards us, that has been entrenched in our culture for thousands of years may prevent us from thinking of food as something we could potentially reject. Additionally, the word "meat" comes from the Old English word "mete," which literally means food (OED). The narrower understanding of the word "meat" as animal flesh used for food was not introduced until the 1300s, demonstrating that "meat" and "food" have long been thought of as effectively the same thing (OED). So, if food is meat, and food protects us, then we may understand meat as something protects us, and why would we consider anything that protects us to be a bad thing?

Jessica has been faced with that question from members of her family, and has been trying for a long time to get them to accept her decision not to eat meat. However, she explains that there are some who still just do not understand.

I just don't feel comfortable eating meat, that's all I can say, it's kind of my mantra - no thank you, it just makes me uncomfortable. Why not? It just makes 
me uncomfortable. Just a little? It just makes me uncomfortable. But it's so good! It just makes me uncomfortable. There's not much I can say after years of that. (Jessica)

The mystery element of food can also add a layer of difficulty for a vegetarian, both in terms of knowing what they can eat and in explaining it to others. When I was young, I had the hardest time explaining to my friends why I could not eat gelatin. Even those who understood why I did not eat hot dogs and hamburgers had a difficult time understanding why I did not eat Skittles or flavored Yoplait yogurt. You mean this is made with grounded up horse hooves? But you can't even tell! No one will know. Just eat it, it's yummy! Much of the food that is available to us today includes ingredients with origins we may not be entirely sure of, so thinking about the minute and possibly invisible ingredients in our food may be somewhat of a foreign concept to many. However, something that may seem unimportant to non-vegetarians may be critical to a vegetarian. Gelatin, lard, rennet, fish sauce, and chicken stock are all commonly used ingredients that may be hard to recognize by the name of a product, or even sometimes the taste of it. Malia has run into this problem a number of times. As a vegan, she has the added burden of figuring out whether or not there are eggs, butter, or whey derivatives in her food:

Sometimes when I don't know what the ingredients to a certain food product are, it is especially difficult for people to understand me. They always say, oh just eat it, it's not a big deal, but they don't understand what a big deal it really is to me. "May contain whey products" doesn't mean the same thing to them as it does to me. Sometimes it upsets me because they try to pressure me into eating it, but they have a lot more lenient ideas about it than I do. (Malia)

Something as simple and seemingly safe as a cookie, for instance, is probably difficult for Malia to explain, while others tend to see it as a normal, acceptable, and harmless food item.

Because meat as food is such a normal part of most peoples' everyday lives, vegetarians may find themselves feeling the need to defend the fact that something so normal for others is not normal for them. Vegetarians have a different relationship with the world of food than nonvegetarians do, and it may seem difficult to explain that relationship to those for whom meat as food is normal. For people with allergies to certain foods, explaining their avoidance of those foods may be more understandable to others - because the avoidance of food is for medical reasons, and they simply are victim of their medical condition. For those who adopt dietary restrictions for religious reasons, explaining their avoidance of certain foods also has a concrete reason. However, many vegetarians choose a non-meat-eating lifestyle for non-medical and nonreligious reasons. When vegetarianism is purely a personal choice (as opposed to allergies or religion), it can sometimes comes across as more flexible of a lifestyle than vegetarians themselves think it is. I sometimes find myself hiding behind a fabricated physiological reaction to meat, It's been so long since I've had meat, my body can't handle it, when attempting to ward off those who seem not to understand that I simply would rather not eat meat. Similarly, a few times Jessica has actually told people that she is a vegetarian for religious reasons, when in fact she is not, just to make it easier for them to understand. "It makes it a lot easier to have that to fall back on" (Jessica). Malia has also related her food choices to religion when attempting to explain her veganism to others: 
I remember my freshman year there were a lot of my friends who were Jewish, and during Passover they couldn't eat bread, and they were complaining to me about wanting a sandwich. I think I said something like, well then just eat one and they were like, I can't because it's my religion. Then I would say, well you know, there are no vegan options either, but they would say, well you choose to be vegan and I was like, yeah but you chose to observe this certain aspect of Judaism too. (Malia)

Comparing one's dietary choices to other restrictive food diets (in the case of allergies or religion) may relieve a sense of loneliness a vegetarian feels on the outside of a culture for which meat is food. Connecting their choices to those other minority food cultures that are sometimes more easily explained, may ease the burden of defending the different relationship to food that vegetarians have chosen to adopt.

The normalcy of meat as food not only gives people difficulty in understanding why a vegetarian diet is strict and important to a vegetarian, it also makes it difficult for people to stop eating meat, even if they might agree with the reasons why some vegetarians choose not to eat meat. Elizabeth Telfer (1996) explains that,

Peoples' desire for nice food [leads] them to do what they themselves [admit is] wrong ... people happily acquiesce in cruel farming practices used to produce their food, rather than choose a diet which does not depend on cruelty but is less attractive to them. (p. 112)

Food that is normal and familiar, as meat is for many people, is a much easier choice and a much more comfortable way of being with the world, despite potentially disturbing information about where that food comes from. Telfer (1996) goes on to describe a conversation she had with a friend of hers in which she tells her friend that there is truth to the arguments in favor of vegetarianism: "Of course there is," her friend says, "but meat is nice” (p. 112). For many, meat is not only nice tasting, but it is a cultural norm and a connection to happy memories. When most people are craving a home cooked meal or their grandmother's signature dish, they are usually thinking about something with meat in it. In these situations, food is a way of reminiscing in a familiar experience - an experience that is normal, culturally accepted, and widely shared. Thus, eating meat can be done easily without having to think about the origins of that meat. Vegetarians, however, may think an abnormal amount about the origins of their food - so much so that it makes the normal experience of meat as food an uncomfortable one. What is "normal" to most may be abnormal to a vegetarian.

\section{Don't Want To Argue About Food: Fearing J udgment from Others}

In the company of someone who chooses a different lifestyle than your own, one may feel a heightened sense of awareness surrounding their own lifestyle choices. Sometimes this can manifest into a fear that one person is judging the other, which can then lead to a feeling of isolation or exclusion. As van Manen and Levering (1996) explain, this feeling of exclusion can 
often stem from a simple misunderstanding. To prevent any potential misunderstandings, vegetarians may feel the need to overtly assert their non-judgment of those who eat meat, even if they secretly feel sadness over the food choices others have made. Jessica often hesitates to tell people that she is a vegetarian because of what others might perceive her to be thinking of them.

I guess I just feel like it's such a personal choice. Like choosing to not eat meat is somehow condemning that they do eat meat, and that they're a terrible person or I don't agree with their choices, and that just opens up a whole can of worms (Jessica).

She is afraid that by explaining her disgust with the act of killing animals (which she states as one of her primary reasons for being vegetarian), that she will offend those that she deeply cares about who kill animals. Yet, she admits to hoping that her children will learn to see meat as she does - as beautiful creatures that have been killed unjustly. "I would absolutely be happy if they shared a sensitivity and a love for animals!” (Jessica) However, despite this secret desire of hers, she chooses not to verbalize it to her family or her children, for fear of making them uncomfortable.

A common stereotype of vegetarians is that they are socially and politically opinionated, and are actively attempting to change the dominant meat-eating culture. Peter Singer (1992), a well-known vegetarian activist, epitomizes this stereotype with his infamously bold statements:

We should write to our political representatives, we should make our friends aware of these issues, we should educate our children to be concerned about the welfare of all sentient beings, and we should protest publicly on behalf of nonhuman animals whenever we have an effective opportunity to do so. (p. 173)

However, many vegetarians do not want to ruffle any feathers, and just want to go about their daily lives. Jessica, for example, shares the following:

I'm not prepared to take that on. I mean, my life is so crazy, raising children and school and all of that, I'm not ready to make a social stand for this issue, so I kind of waddle my way through the easiest way possible... the path of least resistance. I don't feel like I'm a very good role model for vegetarianism ... I'm not marching ... so I don't feel like I can really jump on the bandwagon and give the spiel either (Jessica).

As a possible reaction to this assumption, vegetarians may make an effort to rebuff the activist stereotype before others even have a chance to pin it on them. Knowing that someone may feel judged by you simply because of what you have chosen to eat can be a very ominous feeling, and it would be a shame to push people away without them getting the chance to know you beyond your vegetarianism. Malia describes it as follows: "it's easy for them to just be like, she's the one who doesn't eat meat, and then I'm like, no wait, there's more about me, hold up." Even though Malia sees her veganism as an important part of her identity - and a reflection of who she is in a broader sense - she feels frightened that others will interpret her veganism differently than she interprets it for herself; that without the chance for a deeper conversation, the chances for the misunderstandings that van Manen and Levering (1996) mention are high. 
Why, though, might our food choices be such a taboo topic to discuss? Why might vegetarians fear the perception that others may have of them? Even those who would gladly tell you their religious beliefs (which may also be seen as inherently condemning of others) are cautious about "spilling the beans" about their vegetarianism. Might it be that questioning our food choices, in a sense, questions our very existence and identity as we have come to know it for our entire lives? Heidegger, in 1949, likened the "motorized food industry" to "gas chambers in concentration camps" (Steeves, 2006, p. 51). Merleau-Ponty (1964) later commented that, "Heidegger's ... assertion takes on utterly chilling consequences: insofar as the Jews perish with and like the animals who die in meat-processing plants, that is as essentially similar 'fabrications' of the military-industrial-agricultural complex, they cannot be human ... [and are thus slaughtered] with impunity" (Steeves, 2006, p. 51). All people may not necessarily interpret the implications of such an argument in the same way. As Steeves (2006) notes,

One can read Heidegger as lowering the horror of the Holocaust to the level of the carnivorous food industry, rather than raising the tragedy of the carnivorous food industry to the level of that greatest tragedy, the Holocaust. The lowering, no doubt, springs from evil intent. The raising is nobler, though perhaps unutterable. (p. 51)

Perhaps even suggesting, as Steeves (2006) does, that it would be noble to bring the rights of animals to the same level as the rights of humans is unutterable. My own hesitation to include such a suggestion in a piece of writing that will be seen and heard by others may demonstrate the weight that it carries; however, it still may be a valuable consideration to make.

Surely, questioning the morality of our food choices is a difficult and uncommon thing to do. Our parents gave us this food and most people eat it on a regular basis, so what is there to question? They are good people, so why would their food be anything but good? If I feel uncomfortable with the practices of the food industry does that mean I also have to question those who support it (by eating meat)? Even posing such questions to oneself can be unnerving, as it may mean calling into question their daily actions as a reflection of their own ethics and principles. For vegetarians, this problem may become even more difficult when asked to explain their reasoning for choosing vegetarianism - whatever it may be: animal cruelty, environmentalism, health, etc. - without seemingly passing judgment upon others. As such, vegetarians may become hypersensitive to others' perceptions of them when discussing food, possibly causing them to refrain from speaking or acting as they normally would. Some vegetarians, in an attempt to protect the feelings of others, may hide their vegetarianism altogether. This can be difficult in social situations that involve food, but the effort to "stay in the closet” is perhaps there even if they are "outted" against their will. Unfortunately, this can leave vegetarians with a secret that they must deal with all on their own, rather than being able to be honest with others about what they are thinking. A vegetarian might think, am I truly able to enjoy social, food-inclusive, situations as much as others are? Van Manen and Levering (1996) suggest that,

We can only enjoy good social relationships ... to the extent that we are willing to share our thoughts and be open with the people around us. Without mutual openness and the general willingness to be truthful, social interactions and conversations become pointless. (p. 55) 
So, might it be possible that the inability of a non-vegetarian host to say, "you are such an inconvenience," when serving a vegetarian, or the inability of a vegetarian to say, "I don't like this food, I wish I didn't have to eat here," when dining with his/her non-vegetarian friends prevent the two groups from having a good time together? Emmanuel Kant takes this idea a bit further by arguing that, "to be able to get along, people must be truthful with one another" (van Manen \& Levering, 1996, p. 55). Does this mean that vegetarians and non-vegetarians find it difficult to get along with each other in general because of the perceived need to be untruthful? Maybe. Maybe this is why vegetarians might feel the need to put so much effort into either hiding their vegetarianism or downplaying their own basic need to eat in some scenarios. Maybe this means that in order to prevent negative social ramifications, vegetarians are sometimes forced to lie about how truly hungry or unsatisfied they are with a meal, putting the distance of an untold truth between them and potential (and/or current) relationships. Deane Curtin (1992) wrote that, "Vegetarianism can be seen as a political act of self-empowerment that resists the externalizing pressures of society. To choose one's food and define oneself by that choice in opposition to a dominant conceptual scheme is empowering” (pp. 132-133). While this may be true for some, choosing to use your life and each meal in your day as a political statement may cause people to judge you for judging them; and out of fear of being judged for judging others, some may choose to simply keep their food choices a secret.

\section{Conclusion}

Commonalities in the experiences of the vegetarian/vegan women who have served as my guides in this phenomenological investigation - experiences that have also resonated with my own experience as a vegetarian woman - have uncovered several aspects of a vegetarian or vegan lifestyle that may be somewhat hidden in the hustle and bustle of daily life. First, these women often found themselves in a state of worry over how their personal food choices would impact their ability to build new relationships, sustain current relationships, and adequately share meals with, host, or be hosted by non-vegetarians. Anna Kirova's (2005) explanation that loneliness precludes our ability to feel close to others can help us understand how when these women felt worried, and alone in their thoughts, they struggled to feel the bonds of friendship that food often helps to facilitate in social contexts.

Moreover, due to their inability to experience such regularly occurring situations, as meals are, in a "normal” way, these women's experiences with vegetarianism/veganism left them feeling like outsiders in the world of food. What non-vegetarians may experience as celebratory and joyous occasions (i.e., holidays, family reunions, birthdays, company parties, etc.), these women experience as moments that accentuate how different their relationship to food is from those who are not vegetarian. To elucidate the experience of feeling like an outsider, Jean Hyppolite (1956) describes that a natural division exists between "insiders" and "outsiders" where outsiders feel alienated from those on the inside. Gaston Bachelard (1994) expands that notion by suggesting that this separation can cause feelings of anger and isolation. Thus, it is possible that vegetarians, by nature of their abnormal relationship to food, may feel isolated, or even angry about being left on the outside of a food related experience.

Lastly, these women shared the experience of feeling fearful that meat-eaters would perceive them as being critical of their food choices simply because they are vegetarian/vegan. 
Whether their fears were founded on truths or not, they still experienced hesitance about admitting to or talking about their vegetarian lifestyle. As van Manen and Levering (1996) discuss, without the ability to be truthful with others, we cannot truly enjoy social situations, nor can we develop genuine relationships. This may show us why vegetarians might feel reluctant to reveal their diet, and their reasons for choosing that diet with non-vegetarians in order to prevent misunderstandings about possible judgmental opinions.

Insights from the experiences of these women show us just how complex the issue of food can be, however "normal" and innocuous it may seem on the surface. For vegetarians, because they are in the minority with regard to their food choices, the issue may be even more complex than the meat-eating majority perceives it to be. Despite popular opinion that vegetarianism has become a more common choice in recent years, Gallup polls show that the numbers remain virtually unchanged (Gallup, 2012). In 2012, five percent of people in the United States (which is the country of context for this investigation) defined their diet as vegetarian, while two percent defined their diet as vegan (Gallup, 2012). These results showed no substantial difference from their polls in 2001 and 1999. Thus since vegetarians continue to be a minority food culture, bringing forth their lived experiences is an important way to inform the majority of the emotions that may be brewing beneath the surface of their vegetarian/vegan friends and loved ones.

My hope is that through human science research on the lived experience of vegetarians, those who were previously unaware of these experiences can become sensitive to those who choose not to eat meat. While my journey through the lives of vegetarians has been brief, it has nonetheless been enlightening. Even I - one whose adventure with vegetarianism has been lifelong - have gained invaluable knowledge, understanding, and perspective by engaging in phenomenological interaction with other vegetarians. Perhaps others will be benefit similarly from this research.

\section{References}

Abram, D. (1996). The spell of the sensuous: Perception and language in a more-than-human world. New York: Pantheon Books.

Bachelard, G. (1994). The poetics of space. Boston: Beacon Press.

Curtin, D. W. (1992). Recipes for values. In D.W. Curtin \& L.M. Heldke (Eds.), Cooking, eating, thinking: Transformative philosophies of food (pp. 123-144). Bloomington: Indiana University Press.

Gallup. (2012). In the U.S. 5\% consider themselves vegetarian. Retrieved from: http://www.gallup.com/poll/156215/consider-themselves-vegetarians.aspx

Hyppolite, J. (1956). Genèse et structure de la Phénoménologie de l'esprit de Hegel. Paris: Aubier.

Kirova, A. (2005). When a child feels left alone. In M. van Manen (Ed.), Writing in the dark (pp. 156-165). Ontario: The Althouse Press. 
Merleau-Ponty, M. (1964). Sense and non-sense. Evanston, Ill.: Northwestern University Press.

Online Etymology Dictionary. http://www.etymonline.com. Retrieved April 23, 2011.

Singer, P. (1992). Becoming a vegetarian. In D.W. Curtin \& L.M. Heldke (Eds.), Cooking, eating, thinking: Transformative philosophies of food (pp. 172-193). Bloomington: Indiana University Press.

Steeves, H. P. (2006). The things themselves: Phenomenology and the return to the everyday. Albany, NY: State University of New York Press.

Telfer, E. (1996). Food for thought: Philosophy and food. London: Routledge.

van Manen, M., \& Levering, B. (1996). Childhood's secrets: Intimacy, privacy, and the self reconsidered. New York: Teachers College Press.

\footnotetext{
${ }^{\mathrm{i}}$ In order to maintain the confidentiality of my research participants, I have replaced all names with pseudonyms.
} 